\title{
Impact of cleft lip and/or palate in children on family quality of life before and after reconstructive surgery
}

\author{
Macho P, Bohac M, Fedeles J Jr, Fekiacova D, Fedeles J Sr \\ Clinic for Plastic, Aesthetic and Reconstructive Surgery Medical Faculty, Comenius University Hospital, \\ Bratislava, Slovakia. machopaloo@yahoo.com
}

\begin{abstract}
BACKGROUND: The aim of the study was to evaluate the impact of cleft lip/palate children together with consequent treatment on quality of family life using standardized questionnaire. Different to previous studies the evaluation of quality of family life by questionnaire was realized twice in the same group of families (before the reconstructive surgery and several months after palatoplasty).

METHODS: The study was conducted in 40 families divided in two groups: 20 families with children with cleft lip (CL), 20 families with children with cleft lip and palate (CLP). The questionnaire of the Impact on Family Scale was used for evaluation of the influence of orofacial clefts on parent's quality of life. Evaluations were made at the second month of child's life and at one year of child's life with reciprocally comparison.

RESULTS: The higher impact of children with CLP on quality of family life was noted at 2 months and 1 year of child's age as compared to the impact of children with CL. The reduction of impact on quality of life after surgical correction was observed in families of children with $C L$ at one year of child's age. This decrease of influence on family quality of life was due to significantly lower impact in strain and economic dimensions in families with CL children after operation. However, in the group of families with CLP children no significant changes in the impact on family quality of life were noted when compared to the values before and shortly after the reconstructive surgery.

CONCLUSIONS: This study showed that orofacial clefts in children influence markedly the quality of their family life. The higher impact of children with CLP on quality of family life as compared to children with CL was noted and this impact in CLP group was not influenced shortly after reconstructive surgery. It is suggested that appropriate medical care in Cleft Centre with special psychological support may lead to improvement in quality of life for families with cleft lip and palate children (Tab. 2, Fig. 2, Ref. 14). Text in PDF www.elis.sk.

KEY WORDS: cleft lip, cleft palate, quality of life, the impact in family scale.
\end{abstract}

\section{Introduction}

The increasing attention in medical care is focused on the studies of impact of chronic illness and disability in children on family life $(1,2,3,4,5)$. Cleft of lip and palate is one of the most common congenital craniofacial malformation that may impose a large burden on the psycho-socio-economic well-being of the affected individuals and their families $(6,7,8)$. Newborns with cleft lip or cleft lip with palate have acquired stigmatized face, what leads parents to new challenge, which has to be overcome. Whole after-birth period together with post-operation phase impacts the patient's quality of life and mainly influences their parents $(6,7,9$, 10). However, the number of clinical studies evaluating the impact of children with cleft lip/palate on the family life is relatively small $(6,7,9,10,11)$. This was the reason for realization of this study evaluating the quality of life in parents of children registered in

Clinic for Plastic, Aesthetic and Reconstructive Surgery Medical Faculty, Comenius University Hospital, Bratislava, Slovakia

Address for correspondence: P. Macho, MD, Clinic for Plastic, Aesthetic and Reconstructive Surgery Medical Faculty, Comenius University Hospital, Bratislava, Ruzinovska 6, SK-826 06, Bratislava, Slovakia. our Cleft Centre. The aim of the study was to evaluate the impact of cleft lip/palate children together with consequent treatment on quality of family life using standardized questionnaire. Different from previous studies $(9,10,11)$, the evaluation of quality of family life by questionnaire was realized twice in the same groups of families. The first questionnaire was filled out the second month of children's life (before the operation), the second questionnaire was filled out after reconstructive surgery at the time of the first year of child's age.

\section{Patients and method}

Patients with cleft lip (CL) or with cleft lip and palate (CLP), who were treated in Cleft Centre at the Clinic for Plastic Surgery, Comenius University Hospital, Bratislava and their families were included in this study. Inclusion criteria for entry the prospective 5 years running study were fulfilled by 40 families, and these families were divided in two equal groups. The first group included 20 families with children affected by cleft lip only. The second group included equally 20 families with children with cleft lip and palate. Lip correction was realized in the third month of patient's life. In case of need (for cleft lip and palate children), the palate 
closure was realized at the sixth month of patient's life. All procedures were performed according to operation protocol valid in our Cleft Centre. The informed consent was obtained from all participating families.

The impact on family scale questionnaire (12) was used for evaluating the impact of cleft lip/palate and following operative treatment on the quality of parent's life. The questionnaire was filled first time at the second month of child's age (before the operation), than the second questionnaire with the same questions at the age of one year of affected child with correlative comparison. The questionnaire involves 27 questions with one of four possible answers in points (high impact 4 points - low impact 1 point) and the degree of impact on family was quantified by reached points. Four dimensions in the questionnaire were marked as the most important and analyzed: economic (changes in the family's economic status, 6 items), social (the quality and quantity of interaction with other persons outside the family, 4 items), familial (quality of interaction within the family unit, 7 items) and strain (subjective burden experienced by the primary caretaker, 10 items). The data were analyzed using statistical t-test method and SPSS software version 10.0.

\section{Results}

The comparison of averages of total points in the group of families of children with cleft lip only to the group of patients with cleft lip and palate showed higher impact of combined cleft lip and palate on family life (Tab. 1). The differences were significant at 2 months and also at 1 year of children age. The significant de-

Tab. 1. Mean values of total points and medians from Impact on family scale questionnaire.

\begin{tabular}{lcccc}
\hline Group & $\begin{array}{c}\text { CL } \\
\text { 2 months }\end{array}$ & $\begin{array}{c}\text { CL } \\
\text { 1 year }\end{array}$ & $\begin{array}{c}\text { CLP } \\
\text { 2 months }\end{array}$ & $\begin{array}{c}\text { CLP } \\
\text { 1 year }\end{array}$ \\
\hline Number of values & 20 & 20 & 20 & 20 \\
MEAN \pm SE & $56.9 \pm 2.93$ & $50.9 \pm 2.83^{*}$ & $64.9 \pm 2.81 \ddagger$ & $62.0 \pm 3.06 \%$ \\
Median & 55.5 & 47.0 & 62.0 & 60.5 \\
$25 \%$ percentil & 48.0 & 44.0 & 57.0 & 48.0 \\
$75 \%$ percentil & 64.8 & 53.8 & 70.0 & 72.0 \\
\hline
\end{tabular}

$\overline{\mathrm{CL} \text { - families with children with cleft lip, CLP- families with children with cleft lip }}$ and palate 2 months, 1 year - the age of children at the collection of questionnaire. Statistical significance of differences: ${ }^{*} \mathrm{CL} 2$ months: CL 1 year $\mathrm{p} \leq 0.05,+\mathrm{CL}$ group: CLP group $\mathrm{p} \leq 0.05$

Tab. 2. Mean values of points from individual items in dimensions of impact of familiy scale questionnaire.

\begin{tabular}{lcccccc}
\hline \multirow{2}{*}{ Group } & \multicolumn{3}{c}{ CL } & & \multicolumn{2}{c}{ CLP } \\
\cline { 3 - 4 } \cline { 6 - 7 } & & 2 months & 1 year & & 2 months & 1 year \\
\hline Dimension & items & & & & & \\
Economic & 6 & $1.55 \pm 0.09$ & $1.35 \pm 0.07^{*}$ & & $2.07 \pm 0.11 \S \S$ & $1.91 \pm 0.10 \S$ \\
Social & 4 & $1.45 \pm 0.05$ & $1.26 \pm 0.06$ & & $1.93 \pm 0.12 \S$ & $1.60 \pm 0.10^{*}$ \\
Familial & 7 & $2.91 \pm 0.11$ & $2.81 \pm 0.11$ & & $3.08 \pm 0.10$ & $3.03 \pm 0.10$ \\
Strain & 10 & $2.13 \pm 0.08$ & $1.80 \pm 0.06^{* *}$ & & $2.31 \pm 0.08$ & $2.28 \pm 0.08 \S$ \\
\hline
\end{tabular}

CL - families with cleft lip children, CLP - families with children with cleft lip and palate 2 months, 1 year - the age of children. Statistical significance of differences between groups: 2 months: 1 year $* \mathrm{p} \leq 0.05, * * \mathrm{p} \leq 0.01, \mathrm{CL}-\mathrm{CLP} \S \mathrm{p} \leq 0.05$ $\S \S \mathrm{p} \leq 0.01$

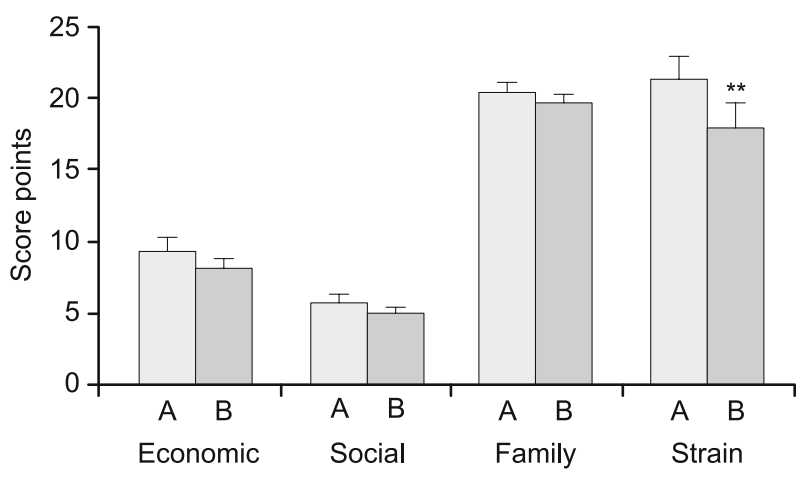

Fig. 1. The average score of points of impact of family scale questionnaire in economic, social, family and strain dimensions of families with children with cleft lip. A - 2 months, B - 1 year of age of children with orofacial defect.

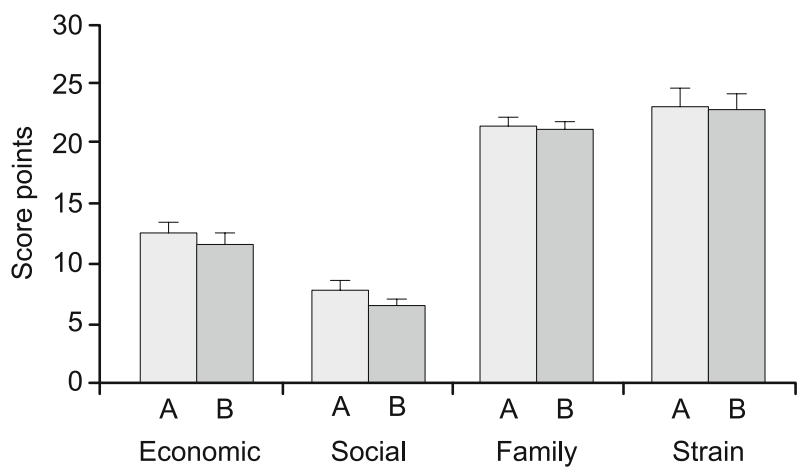

Fig. 2. The average score of points of impact of family scale questionnaire in economic, social, family and strain dimensions in families with children with cleft lip and palate. A- 2 months, B - 1 year of age of children with orofacial defect.

crease of the average of total points $(11.5 \%)(\mathrm{p}<0.05)$ was noted in the families of children with CL after reconstructive surgery at the age of one year (Tab. 1). However no significant changes in impact on family life were noted in the group of children with CLP after the operation.

The average scores of impact on family life in economic and social dimensions in the questionnaire were lower in comparison to familial and strain dimensions in both CL (Fig. 1) and CLP groups (Fig. 2) at 2 months and also at 1 year of child's age. Significant decrease in average of score points in strain dimension (anxiety feelings) on quality of life was observed in families with CL children after operations (Fig. 1, $15.9 \%$ decrease, $p<0.001$ ). However, the score in other dimensions (social, familial) decreased only slightly and improvement of the quality of life was not significant. There were no significant differences in average values of the score of points in economic, social, familial and strain dimensions before and after the surgery in families with children with cleft lip and palate (Fig. 2).

The average of number of points in response to individual items of questionnaire in the four dimensions showed that there are differences in the impact of dimensions on quality of life in 


\section{0-373}

families of children with CL or CLP. Higher impacts of familial and strain dimensions were noted in all groups as compared to economic (financial) and social dimensions (Tab. 2). In families having children with CLP higher impact of economic and social dimensions in comparison to $\mathrm{CL}$ was observed at the age of children of 2 months and also 1 year (Tab. 2). The significant difference between CL and CLP groups was also noted in strain dimensions in children 1 year of age, mainly due to decrease of impact on quality of life in CL group after reconstructive surgery in children (Tab. 2).

\section{Discussion}

The detailed knowledge of impacts influencing the quality of life in families having children with clef lips or clef lift and palate might support affected families in coping with the particular situation and providing adequate care for the patients (6). Most of the previous studies on the effects of oral clefts in children on quality of life of families have been conducted at different ages with different groups of children and at various periods after palatoplasty $(9,10,11,13,14)$. There were no observations on the impact of orofacial defects in children on the quality of family life before the operation, thus it was not possible to evaluate the effects of reconstructive operations. Results of our five years long running prospective study show evaluation of the impact of cleft lip/palate in children on parent's quality of life during the first two months of child's life (before the operation) and also at the end of first year (after reconstructive surgery). This made it possible to compare the immediate effects of reconstructive surgery of clefts on quality of family life. In the contrary to our expectation the results revealed low impact of orofacial cleft of children on social interactions and economic burden of family, but very high influence on family interactions and strain.

The results of our observations during the early period of life of children with oral clefts showed differences in the impact of various dimensions of life in families with CL or CLP on quality of family life. The economic impact was represented by increased costs for frequent visits for out-patient examinations, (the need for operative correction at three months and subsequent controls), the stop in work due to care for a child, causing financial problems for family. The impact of economic dimension on quality of life in our study was not so high as compared to familial and strain dimensions. This is due to the fact that in Slovakia the maternity leave takes three years, so the feeling of losing the work for the need of taking care of children has only a low impact.

Social interactions with other people for parents with affected child represent a low impact on quality of life. The mean values of points in social dimension showed the higher impact in CLP group as compared to CL. These results are in agreement with observations of Kramer et al (9), who described that families with older children with CL had smaller reduction in family functioning than families with children with CLP or CP.

The most impacted dimensions influenced by the child's disease were interactions inside the family (represented by the feeling of tightening of the relationship in the family, the need for com- munication with partner, the feeling of having not enough time for other members in the family, making the effort for treating the child as a healthy one). The score of impact in this familial dimension was not influenced by reconstructive surgery of the defects after this short period after operation.

The strain (subjective feeling of burden, fatigue for carry for the child, a worry what happens to the child in the future, interference with relatives) is a dimension also with high influence on the quality of parent's life. Many times strain is presented as feelings not being understood by other people, worries about future, feeling of instability in life in crisis when the child is ill, carelessness when things go allright. However, in this dimension a significant improvement was noted after one year in CL group as compared to the impact of cleft in child before the operation. In families with children with CLP no significant changes in the impact on quality of family life of this dimension were noted at short period after CLP reconstruction. It seems reasonable that longer period after operation in CLP children is necessary to observe also a decrease of impact on quality of life in strain dimension.

In conclusions our prospective study showed, that clefts in children influence markedly the quality of their family life. The higher impact of combined cleft lip and palate of children on quality of family life was noted as compared to the influence of children only with cleft lip. A significant decrease of impact in strain and economic dimensions after reconstructive operation appeared in families of children with cleft lip. However, no changes in impact on family life after operation were noted in families of children with cleft and palate. It is suggested that appropriate medical care in Cleft Centre with special psychological support may lead to improvement in quality of life for families with cleft lip and palate children.

\section{References}

1. Raven-Sieberer U, Morfeld M, Stein RE, Jessop DJ, Bullinger M, Thyen $\mathbf{U}$. The testing and validation of the German version of the impact on family scale in families with children with disabilities. Psychoter Psychosom Med Psychol 2001; 51 (9-10): 384-393.

2. Westbom L. Impact of chronic illness in children on parental living conditions. A population-based study in a Swedish primary care district. Scand J Prim Health Care 1992; 10 (2): 83-90.

3. Eddy LL, Engel JM. The impact of child disability on the family. Rehabil Nurs 2008; 33 (3): 98-103.

4. Caicedo C. Families with special needs children: family health, functioning, and care burden. J Am Psychiatr Nurses Assoc 2014; 20 (6): 398-407.

5. Simsek IE, Erel S, Simsek TT, Atasavun Uysal S, Yakut H, Yakut Y, Uyhur F. Factors related to the impact of chronically disabled children on their families. Pediatr Neurol 2014; 50 (3): 255-261.

6. Krammer FJ, Baethge C, Sinikovic B, Schliephake H. An analysis of quality of life in 130 families having small children with cleft lip/palate using the impact on family scale. Int J Oral Maxillofac Surg 2007; 36 (12): $1146-1152$. 
7. Tapia VJ, Estein S, Tolmach OS, Hassan AS, Chung NN, Gosman AA. Health-related quality-of-life instruments for pediatric patients with diverse facial deformities: A systematic literature review 2016; 138 (1): 175-187.

8. Fedeles J Jr, Ziak P, Krizko M, Payer J Jr, Bohac M, Palencar D, Hulin I Jr, Fedeles J. Prevalence of cleft lip and palate in western Slovakia in the years 2001-2007. Bratisl Lek Listy 2012; 113 (2): 117-119.

9. Kramer FJ, Gruber R, Fialka F, Sinikivic B, Hahn W, Schliephake H. Quality of life in shool-age children with orofacial clefts and their families. J Craniofac Surg 2009; 20 (6): 2061-2066.

10. Wehby G, Cassel CH. The impact of orofacial clefts on quality of life and health care use and costs. Oral Dis 2010; 16 (1): 3-10.
11. Antunes LS, Maues CP, Nadaes MR, Costa MC, Kuchler EC, Antunes LA. The impact of nonsyndromic oral clefts on family quality of life. Spec Care Dentist 2014; 34 (3): 138-143.

12. Stein REK, Jessop DJ, The development of an impact-on family scale: Preliminary findings. Medical Care 1980; 16 (4): 465-471.

13. Awoyale T, Onalaje AT, Ogunnowo BE, Adeyemo WL, Wanyonyi KL, Butali A. Quality of life of family caregivers of children with orofacial clefts inNigeria: aa mixed - method study. Oral Dis 2016; 22 (2): 116-122.

14. Do LG, Spencer AJ. Evaluation of oral health-related quality of life questionnaire in a general child population. Community Dent Health 2008; 25 (4): 205-210.

Received January 20, 2017. Accepted February 15, 2017. 